\title{
Secondary Plant Metabolites of Natural Product Origin-Strongylodon macrobotrys as Pitting Corrosion Inhibitors of Steel around Heavy Salt Deposits in Gabu, Nigeria
}

\author{
Benedict U. Ugi ${ }^{*}{ }^{(0)}$, Victoria M. Bassey ${ }^{1}$, Mbang E. Obeten ${ }^{2}$, Stephen A. Adalikwu ${ }^{3}$, \\ Desmond 0. Nandi ${ }^{1}$ \\ ${ }^{1}$ Department of Pure \& Applied Chemistry, University of Calabar, Calabar, Nigeria \\ ${ }^{2}$ Department of Chemistry, Cross River State University of Technology, Calabar, Nigeria \\ ${ }^{3}$ Department of Chemistry, Cross River State College of Education, Akamkpa, Nigeria \\ Email: *ugibenedict@gmail.com
}

How to cite this paper: Ugi, B.U., Bassey, V.M., Obeten, M.E., Adalikwu, S.A. and Nandi, D.O. (2020) Secondary Plant Metabolites of Natural Product Origin-Strongylodon macrobotrys as Pitting Corrosion Inhibitors of Steel around Heavy Salt Deposits in Gabu, Nigeria. Journal of Materials Science and Chemical Engineering, 8, 38-60. https://doi.org/10.4236/msce.2020.85004

Received: April 21, 2020

Accepted: May 25, 2020

Published: May 28, 2020

Copyright $\odot 2020$ by author(s) and Scientific Research Publishing Inc. This work is licensed under the Creative Commons Attribution International License (CC BY 4.0).

http://creativecommons.org/licenses/by/4.0/ (c) (i) Open Access

\begin{abstract}
Investigation into the Inhibition of pitting corrosion in mild steel around heavy salt deposits by some selected secondary plant metabolites-alkaloid extract (AESML), saponin extract (SESML and flavonoid extract (FESML) of natural product origin-Strongylodon macrobotrys was successfully completed with the aid of electrochemical impedance spectroscopy, potentiodynamic polarization, gravimetric and gasometric experimentation. The research proved that the selected secondary plant metabolites were excellent inhibitors of mild steel in the salt water environment as inhibition efficiency was recorded at $99.2 \%, 92.6 \%$ and $84.7 \%$ for AESML, SESML and FESML. The inhibitors showed higher inhibition at lower temperature due to frequent scale redeposition from agitation in temperature rise and loss in collision of the molecules. The potentiodynamic polarization result confirmed the reduction in the loss of electrons at the anode by the inhibitors that would have trigger oxidation reaction that causes the anode to corrode. Charge transfer resistance reflected the maximum inhibition efficiency obtained for mild steel at maximum concentration and the decrease in double layer capacitance is due to the decrease of the area where electrolyte is present due to the formation of inhibitor film. Thermodynamic investigation shows that the inhibitor has the potential of increasing the energy of the intermediate, reducing both the number of collisions, and number of particles that have enough energy to react and also number of corrosion reaction particles with the correct orientation. The adsorption isotherm consideration shows physical adsorption me-
\end{abstract}


chanism with binding constant increasing with increasing temperature.

\section{Keywords}

Keywords Corrosion, Electrochemistry, Polarization, Adsorption, Strongylodon macrobotrys, Gasometric

\section{Introduction}

Corrosion is the world's most destructive factor of materials most importantly metals, and one very important factor that slows the advancement of industrialization and economic advancement. Normal steel is an alloy of iron and contains up to $1.5 \%$ carbon, sometimes with traces of a few other metals [1]. Due to increased use of metals in modern world, corrosion can cause enormous loss if it occurs. Lives had been lost to corrosion effects; building and bridges have collapsed; leakages of both waste and valuables materials attributed to rust of containers have been verified; breakdown of very valuable and expensive industrial machines has been recorded; road accidents attributed to wears and tears of bolts and nuts at joints have also been established, etc. [2]. From the above mentioned dangers of corrosion, one can indisputably see corrosion as an electrochemical process that causes a material exposed to unfavorable environmental conditions to degrade spontaneously with time leading to threat. There are mainly two factors that affect corrosion-metallic and environmental factors. Metallic factors range from the position of metal in galvanic series, purity of metal, relative areas of anode and cathode, physical state of metal, etc. while the environmental factors include temperature, humidity, atmospheric impurity, $\mathrm{pH}$ value, etc. [1] [3]. The struggle to combat corrosion effects on materials especially metals has come a long way ranging from the use of different protective measures especially environmental modifications, metal selection and surface conditions, cathodic protection, coating, plating to the use of synthesizes inorganic materials that became unhealthy to the environment after usage, and now eco-friendly secondary plant metabolites of natural product [4] [5] [6] [7]. Secondary metabolites are chemicals produced by plants for which no role has yet been found in growth, photosynthesis, reproduction, or other primary functions [8] [9]. They can be classified on the basis of chemical (for example, having rings, containing a sugar), composition (containing nitrogen or not), their solubility in various solvents, or the pathway by which they are synthesized. A simple classification includes three main groups: the terpenes (made from mevalonic acid, composed mostly entirely of carbon and hydrogen), phenolics (made from simple sugars, containing benzene rings, hydrogen and oxygen), and nitrogen-containing compounds (extremely diverse, may also contain sulphur) [7] [10] [11] [12]. Secondary plant metabolites of natural products ranging from alkaloids, tannins, flavonoids, saponins, terpenes, glycosides, etc. are well known to possess to a larger 
extent some hetero atoms like sulphur, phusphorus, nitrogen, and also aromatic tendencies, presence of pi and sigma bonds (double and triple bonds), etc. that have a strong binding tendency on surfaces and the ability to displace water molecules concentrated on such surfaces hence, creating an interface that disallows the action of corrosive substances on such surfaces [2] [13] [14] [15]. Strongylodon macrobotrys as shown in Figure 1, is a striking plant from the pea family Fabaceae. It is an evergreen climber commonly known by the name emerald vine and very dominant in Gabu forest.

It has a vigorous climbing ability and can easily reach $20 \mathrm{~m}$ in height, with possible spread of $4 \mathrm{~m}$. leaves are oval to egg-shapes and measure up to $25 \mathrm{~cm}$ long. The plant grows well under partially shaded conditions of moist, well-draining soil with neutral to slightly acidic $\mathrm{pH}$. Due to the rising need for the elimination of corrosion especially Pitting corrosion in the research area and the complete lack of information on the use of this inhibitor and the study area, the researchers decided to carry out this research aimed at investigating the use of secondary metabolites of natural product origin from same location as pitting corrosion inhibitors of steel around heavy salt deposits in Gabu Community of Yala Local Government Area in Nigeria.

\section{Experimentation}

\subsection{Preparation of Standard Solution and Metal Dressing}

A raw water sample which was collected in $1000 \mathrm{ml}$ container and evaporated left a salt deposit $(\mathrm{NaCl})$ of about $12 \mathrm{~g}$. Hence the raw water which was now been described with a concentration of $0.2 \mathrm{M}$ standard solution was used for the experimentation and serial dilution into the various inhibitor concentrations of $0.5,1.0,2.0,3.5,5.0 \mathrm{~g} / \mathrm{L}$ was carried out, while the raw water was used as the control $(0.2 \mathrm{M} \mathrm{NaCl})$. The metal used for this work was obtained from a dilapidated overhead water tank in Gabu secondary school and was resized in the dimension $3.5 \mathrm{~cm} \times 0.1 \mathrm{~cm} \times 3.5 \mathrm{~cm}$ for gravimetric analysis, $2.0 \mathrm{~cm} \times 0.1 \mathrm{~cm} \times$ $2.0 \mathrm{~cm}$ for gasometric analysis and $1 \mathrm{~cm} \times 1 \mathrm{~cm}$ for electrochemical methods. All the resized metals were adequately polished with electronic UNIPOL-820 metallographic polishing machine to a mirror surface and stored in a moisture free desiccator.

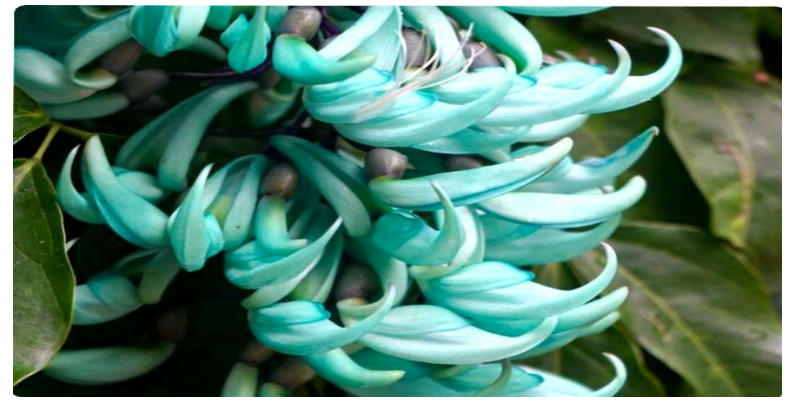

Figure 1. Strongylodon macrobotrys. 


\subsection{Extraction of Crude Extracts of Strongylodon macrobotrys}

After preliminary preparation of the leaves, a MEMMERT WNB-14 laboratory Oven was employed in the drying of the leaves at a temperature low enough $\left(500^{\circ} \mathrm{C}\right)$ to avoid loss of volatile organic constituents present. Small surface area of the dried leaves was obtained by grinding using mortar and pistil followed by a grinding engine then sieved. A sucxhlet extractor and $500 \mathrm{ml}$ ethanol as extraction solvent was adopted for the extraction of the crude ethanol extracts ahead of the preparation of the stock solution of various experimental secondary metabolites. The crude extract obtained after extraction was evaporated in a water bath and stored for use.

\subsection{Preparation of Inhibitor Stock Solution}

\subsubsection{Extraction of Alkaloids}

Extraction of alkaloid extracts of Strongylodon macrobotrys was possible with the use of diethyl ether, $0.5 \mathrm{M} \mathrm{HCl}$ acid and ammonia. A $1000 \mathrm{ml}$ separating funnel was used to host $50 \mathrm{~g}$ of crude ethanol extract of Strongylodon macrobotrys and $250 \mathrm{ml}$ of $0.5 \mathrm{M} \mathrm{HCl}$ and diethyl ether each. The funnel was stoppered properly and the content shook to attain homogeneity. The mixture was allowed to stand for 3 hours after which the tailing content was separated and the top portion basified with ammonia and $250 \mathrm{ml}$ of diethyl ether added for separation and kept for another 3 hours. The mixture was partitioned in the separating funnel and the tailing content was the collected and evaporated over a water bath. The remaining content after evaporation was the alkaloids.

\subsubsection{Extraction of Saponins}

The extraction of saponins was possible through the help of metahanol, chloroform and n-butanol. The crude ethanol extract crude (50 g) was digested with 25 $\mathrm{ml}$ of methanol and heated using a water bath for 3 hours. This was followed immediately with the addition of $30 \mathrm{ml}$ of chloroform to enable organic portion separation. The methanol fraction obtained was then diluted with $15 \mathrm{ml} \mathrm{n}$-butanol, mixed properly and heated gently to evaporate the n-butanol until dryness to obtain a crystalline soapy extract used as saponins.

\subsubsection{Extraction of Flavonoids}

Extraction of flavonoids followed the use of $80 \mathrm{~g}$ of the powdered leaves and extracted with $250 \mathrm{ml}$ ethanol at ambient temperature for 2 hours. The digested solution was then digested in $100 \mathrm{ml}$ of hexane solution to remove lipids and filtered then evaporated at $600^{\circ} \mathrm{C}$ to dryness. This followed the weighing of the extract and the flavonoid extract amount measured. The solution was filtered and the filtrate was evaporated to dryness over water bath at $500^{\circ} \mathrm{C}$.

\subsection{Gravimetric Experimentation}

Hundred $\mathrm{ml}$ graduated beakers were used for this experimentation. $100 \mathrm{ml}$ of each inhibitor (CAESML, CSESML and CFESML) at different concentrations (01, 
1.0, 2.0, 3.5 and $5.0 \mathrm{~g} / \mathrm{L})$ including the control $(0.2 \mathrm{M} \mathrm{NaCl})$ was emptied into each beaker and the previously prepared resized metals $(3.5 \mathrm{~cm} \times 0.1 \mathrm{~cm} \times 3.5$ $\mathrm{cm}$ ) weighed using ADAM PGW 253e electronic digital weighing balance and immersed through the aid of a hanger and thread and the initial time of immersion recorded. Subsequent weighting was carried out after every 60 minutes of immersion preceding washing with distilled water, degreasing with ethanol and rinsing in acetone and air dried. This was observed for each inhibitor and immersion time. Experiment was carried out in triplicate and result averaged for accuracy. Corrosion rate s of metal was obtained from plots using Excel and inhibition efficiency worked out using Equation (1).

$$
I E \%=\frac{W l_{b}-W l_{i}}{W l_{b}} \times 100
$$

\subsection{Gasometric Experimentation}

Gasometric assembly majorly measures the evolution of hydrogen gas as response to level of corrosion by acid or alkaline solution in the presence of heat. $100 \mathrm{ml}$ of each inhibitor (AESML, SESML and FESML) at different concentrations $(01,1.0,2.0,3.5$ and $5.0 \mathrm{~g} / \mathrm{L})$ including the control $(0.2 \mathrm{M} \mathrm{NaCl})$ was emptied into $250 \mathrm{ml}$ conical flask and the previously prepared resized metals $(2.0 \mathrm{~cm}$ $\times 0.1 \mathrm{~cm} \times 2.0 \mathrm{~cm}$ ) immersed directly and the initial paraffin level recorded. The flask was immediately immersed in the water bath regulated to specific temperatures. Subsequent readings were carried out after every 60 seconds of immersion. This was observed for each inhibitor and immersion time and temperature. Experiment was carried out in triplicate and result averaged for accuracy.

\subsection{Electrochemical Experimentation}

The EIS was investigated at ambient temperature in a triple electrode cell compartment using Gamry Reference 600 potentiostart/galvanostart inclusive of a Gamry framework EIS300 system. Echem analyst software was used to analyze the fitting of the data. A saturated calomel (SCE) electrode was introduced as the reference electrode and a $1 \mathrm{~cm}^{2}$ platinum foil was introduced as a counter electrode. The working electrode with dimension $1 \mathrm{~cm} \times 1 \mathrm{~cm}$ was dipped in $0.2 \mathrm{M}$ $\mathrm{NaCl}$ concentrated river water. Electrochemical tests were conducted within a frequency of $10 \mathrm{~Hz}-100,000 \mathrm{~Hz}$ within Potentiodynamic conditions, with an amplitude of $5 \mathrm{mV}$, involving alternating current signal at $E_{\text {corr }}$ All experiments were conducted every $30 \mathrm{~min}$ with and without various concentrations of the inhibitors. From the $R_{c t}$ obtained, the retardation efficiency was calculated using Equation (2):

$$
I E \%=\frac{R i_{c t}-R o_{c t}}{R i_{c t}} \times 100
$$

where $R o_{c t}$ and $R i_{c t}$ represent the charge transfer resistance with and without the inhibitors. 


\subsection{Potentiodynamic Polarization Experimentation}

The behavior of resized steel in the presence of each of AESML, SESML and FESML was investigated by drawing up the anodic site and cathodic site (Tafel) plots. Analysis was carried out on standard alkaline with varied partitions of inhibitors by altering the $\mathrm{eV}$ between -250 to $+250 \mathrm{mV}$ following a scan rate of 1 $\mathrm{mV} / \mathrm{sec}$.

Corrosion current densities values were obtained using Equation (3):

$$
I E \%=\frac{I o_{\text {corr }}-I i_{\text {corr }}}{I o_{\text {corr }}} \times 100
$$

where $I o_{\text {corr }}$ and $I i_{\text {corr }}$ represent the corrosion current density with and without the extract concentrations.

\section{Results}

\subsection{Gravimetric Analysis and Result}

Table 1 shows the finished data analyzed from the gravimetric experimentation with and without various concentrations of AESML, SESML and FESML in alkaline concentrated water. The result shows highest inhibition efficiency of $99.2 \%$, 92.6\% and $84.7 \%$ for AESML, SESML and FESML, respectively. The variation of corrosion rate of metal and inhibition efficiency of inhibitors is shown in Figure 2(a), Figure 2(b). This could be as a result of strong adsorption of the molecules of the various inhibitors on the surface of the steel accounting for adequate replacement of water molecules by the inhibitors [11] [12] [13]. Also the presence of large hydrocarbon components in the major constituent of the plant increase van der Waal attractive force between adjacent molecules as the chain length increases, leading to stronger adsorption at high coverage [12] [14] [15] [16]. The trend in inhibition efficiency AESML $>$ SESML $>$ FESML can be explained from the increased surface area of the AESML on the metal surface compared to others. Also, there could be more of the presence of hetero atoms that improves the inhibition compared to FESML [14] [16] [17] [18] [19] [20]. AESML shows that there may not be any significant change in the efficiency of inhibition if further

Table 1. Gravimetric result showing values of corrosion rates of metal, surface coverage and inhibition efficiency of selected secondary metabolites of natural product origin on mild steel in salt water environment.

\begin{tabular}{cccccccccc}
\hline & \multicolumn{3}{c}{ AESML } & \multicolumn{3}{c}{ SESML } & \multicolumn{3}{c}{ FESML } \\
\hline Conc. $(\mathrm{g} / \mathrm{L})$ & $\begin{array}{c}C R \\
\left(\mathrm{mg} / \mathrm{cm}^{2} / \mathrm{h}\right)\end{array}$ & $\theta$ & $\% I E$ & $\begin{array}{c}C R \\
\left(\mathrm{mg} / \mathrm{cm}^{2} / \mathrm{h}\right)\end{array}$ & $\theta$ & $\% I E$ & $\begin{array}{c}C R \\
\left(\mathrm{mg} / \mathrm{cm}^{2} / \mathrm{h}\right)\end{array}$ & $\theta$ & $\% I E$ \\
\hline Control & 11.019 & - & - & 11.019 & - & - & 11.019 & - & - \\
$0.5 \mathrm{~g} / \mathrm{L}$ & 4.186 & 0.620 & 62.0 & 5.197 & 0.528 & 52.8 & 5.716 & 0.481 & 48.1 \\
$1.0 \mathrm{~g} / \mathrm{L}$ & 3.112 & 0.718 & 71.8 & 5.091 & 0.538 & 53.8 & 5.199 & 0.528 & 52.8 \\
$2.0 \mathrm{~g} / \mathrm{L}$ & 1.870 & 0.830 & 83.0 & 2.118 & 0.808 & 80.8 & 3.854 & 0.650 & 65.0 \\
$3.5 \mathrm{~g} / \mathrm{L}$ & 1.119 & 0.898 & 89.8 & 1.562 & 0.858 & 85.8 & 2.799 & 0.746 & 74.6 \\
$5.0 \mathrm{~g} / \mathrm{L}$ & 0.087 & 0.992 & 99.2 & 0.815 & 0.926 & 92.6 & 1.690 & 0.847 & 84.7 \\
\hline
\end{tabular}




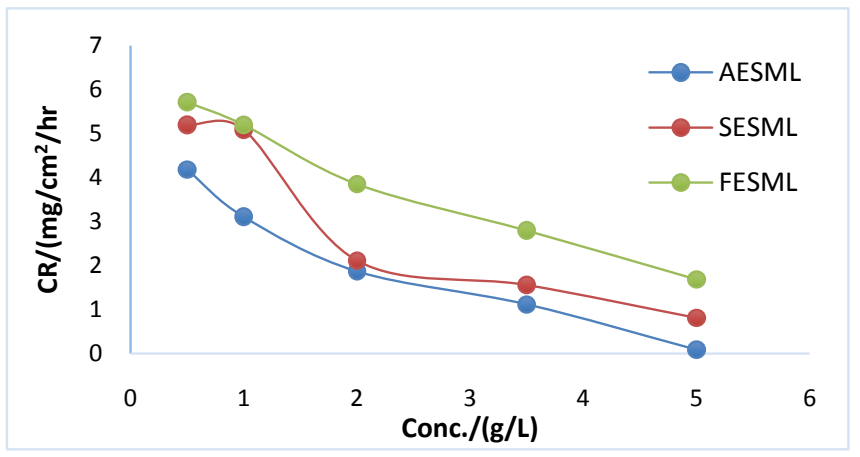

(a)

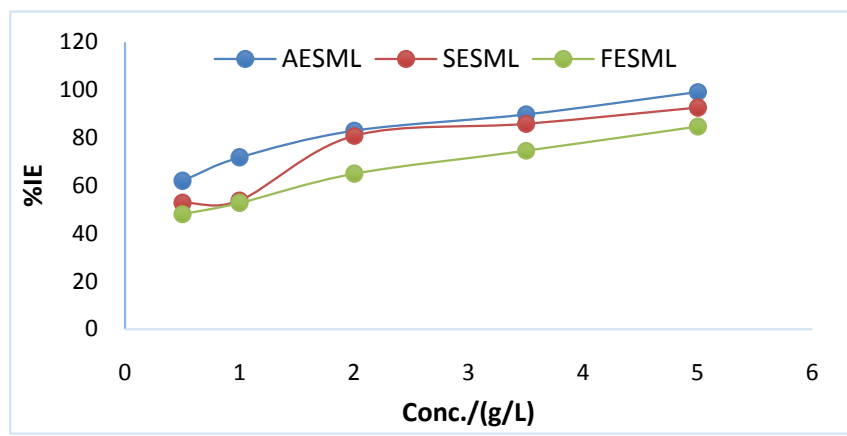

(b)

Figure 2. Plots of (a) corrosion rate of metal and (b) inhibition efficiency against concentration of inhibitors on mild steel in salt water environment.

increase in concentration of the inhibitor was made. This may be explained from that fact at $5.0 \mathrm{~g} / \mathrm{L}$, the concentration of the molecules out way that of the water molecules hence shielding the metal surface especially anodic points from the alkaline attach that would have resulted in further dissolution and increase hydrogen evolution [13] [19] [21] [22]. This gives AESML an advantage over the other two inhibitors.

\subsection{Gasometric Analysis and Results}

Data showing the effect of temperature on both the corrosion rate of steel and the surface coverage and inhibition efficiency of various extracted secondary metabolites of Strongylodon macrobotrys leaves in the presence of water of heavy salt deposit are presented in Table 2 with corresponding graphical sample representation of hydrogen gas evolution against time of experimental immersion in Figures 3(a)-(c). Generally, the result showed increased corrosion rate of the steel with corresponding increase in experimental temperature. This can be explained on the bases of frequent scale redeposition due to agitation in temperature rise and possible desorption of the secondary metabolites inhibitors consequence upon losing collision of the molecules [14] [17] [22] [23] [24] [25]. The surface coverage and inhibition efficiency of the metabolites were seen to have a significant inhibition on the steel with respect to attack of salt deposits on the 
metal at lower temperature but a decrease as temperature rises (though not too significant). Reliable inhibition efficiency demonstrated by the metabolites at various temperatures can be attributed to the presence of hetero atoms in the plant, nature of pi bond and double bonds and structural orientation and aromaticity exhibited by the hetero compounds present. For the slight decrease in inhibition with increased temperature [17] [18] [19] [26] [27] [28] [29] [30], this can be accounted for on the fact that inhibition reaction proceeding relies on the capture of the molecules in a potential well. Increasing the temperature leads to a reduced probability of the colliding molecules capturing one another (with more glancing collisions not leading to reactions the higher momentum carries the colliding particles of the inhibitor out of the potential well), expressed as a reaction cross section that decreases with increasing temperature [15] [16] [27] [31] [32] [33] [34]. This phenomena exhibited by the metabolites however explained physical adsorption mechanism with subsequent shift towards chemisorption [17] [21] [33] [35] [36]. Inhibition efficiency was however seen to take the progression, FESML $<$ SESML $<$ AESML.

Table 2. Gasometric result showing values of corrosion rates of metal, surface coverage coverage and inhibition efficiency of selected secondary metabolites of natural product origin on mild steel in salt water environment.

\begin{tabular}{|c|c|c|c|c|c|c|c|c|c|c|}
\hline & \multirow[b]{2}{*}{ Conc. (g/L) } & \multicolumn{3}{|c|}{$C R\left(\mathrm{mg} / \mathrm{cm}^{2} / \mathrm{h}\right)$} & \multicolumn{3}{|c|}{$\theta$} & \multicolumn{3}{|c|}{$\% I E$} \\
\hline & & $303 \mathrm{~K}$ & $313 \mathrm{~K}$ & $333 \mathrm{~K}$ & $303 \mathrm{~K}$ & $313 \mathrm{~K}$ & $333 \mathrm{~K}$ & $303 \mathrm{~K}$ & $313 \mathrm{~K}$ & $333 \mathrm{~K}$ \\
\hline & Control & 31.765 & 37.188 & 41.114 & - & - & - & - & - & - \\
\hline \multirow[t]{7}{*}{ AESML } & $0.5 \mathrm{~g} / \mathrm{L}$ SESML & 3.011 & 4.564 & 8.173 & 0.905 & 0.877 & 0.801 & 90.5 & 87.7 & 80.1 \\
\hline & $1.0 \mathrm{~g} / \mathrm{L}$ SESML & 2.719 & 4.271 & 7.319 & 0.914 & 0.885 & 0.822 & 91.4 & 88.5 & 82.2 \\
\hline & $2.0 \mathrm{~g} / \mathrm{L}$ SESML & 1.397 & 2.382 & 5.101 & 0.956 & 0.936 & 0.876 & 95.6 & 93.6 & 87.6 \\
\hline & $3.5 \mathrm{~g} / \mathrm{L}$ SESML & 0.814 & 1.323 & 4.294 & 0.974 & 0.964 & 0.896 & 97.4 & 96.4 & 89.6 \\
\hline & $5.0 \mathrm{~g} / \mathrm{L}$ SESML & 0.142 & 0.624 & 2.065 & 0.996 & 0.983 & 0.950 & 99.6 & 98.3 & 95.0 \\
\hline & $0.5 \mathrm{~g} / \mathrm{L}$ SESML & 5.000 & 8.090 & 15.744 & 0.843 & 0.782 & 0.617 & 84.3 & 78.2 & 61.7 \\
\hline & $1.0 \mathrm{~g} / \mathrm{L}$ AESML & 4.177 & 6.997 & 11.796 & 0.869 & 0.812 & 0.713 & 86.9 & 81.2 & 71.3 \\
\hline \multirow[t]{4}{*}{ SESML } & $2.0 \mathrm{~g} / \mathrm{L}$ AESML & 3.016 & 4.713 & 9.793 & 0.905 & 0.873 & 0.762 & 90.5 & 87.3 & 76.2 \\
\hline & $3.5 \mathrm{~g} / \mathrm{L}$ AESML & 1.894 & 3.278 & 6.195 & 0.940 & 0.912 & 0.849 & 94.0 & 91.2 & 84.9 \\
\hline & $5.0 \mathrm{~g} / \mathrm{L}$ AESML & 0.286 & 1.542 & 3.847 & 0.991 & 0.959 & 0.906 & 99.1 & 95.9 & 90.6 \\
\hline & $0.5 \mathrm{~g} / \mathrm{L}$ FESML & 5.324 & 8.274 & 16.977 & 0.832 & 0.778 & 0.587 & 83.2 & 77.8 & 58.7 \\
\hline \multirow[t]{4}{*}{ FESML } & $1.0 \mathrm{~g} / \mathrm{L}$ FESML & 4.725 & 7.109 & 13.634 & 0.851 & 0.809 & 0.668 & 85.1 & 80.9 & 66.8 \\
\hline & $2.0 \mathrm{~g} / \mathrm{L}$ FESML & 3.555 & 5.761 & 10.744 & 0.888 & 0.845 & 0.739 & 88.8 & 84.5 & 73.9 \\
\hline & $3.5 \mathrm{~g} / \mathrm{L}$ FESML & 2.168 & 3.101 & 6.382 & 0.932 & 0.917 & 0.845 & 93.2 & 91.7 & 84.5 \\
\hline & $5.0 \mathrm{~g} / \mathrm{L}$ FESML & 1.038 & 2.558 & 4.517 & 0.967 & 0.931 & 0.890 & 96.7 & 93.1 & 89.0 \\
\hline
\end{tabular}




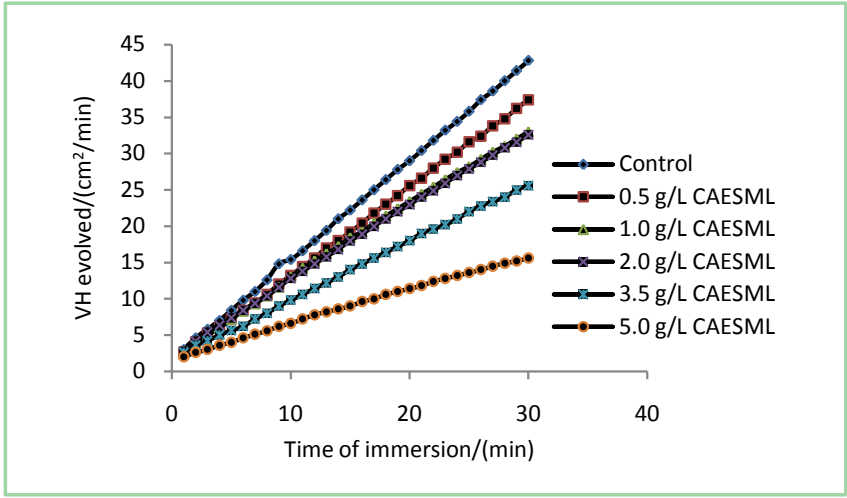

(a)

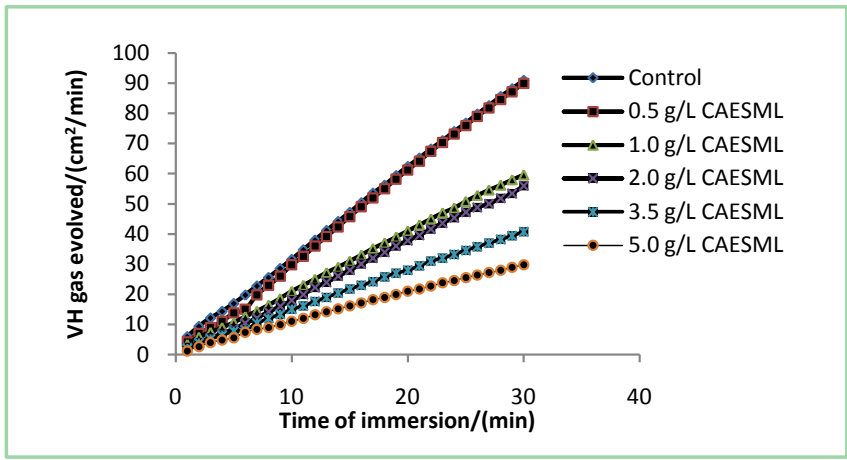

(b)

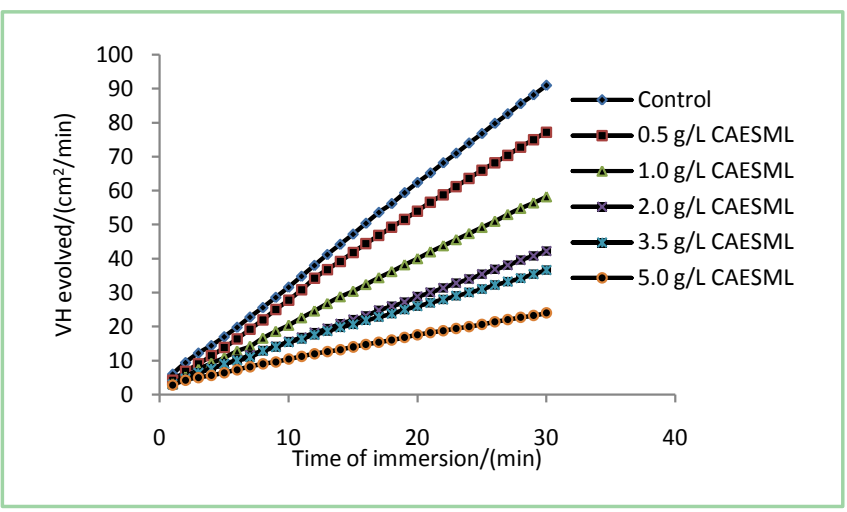

(c)

Figure 3. Representative plots from gasometric data describing the inhibition of alkaloids as secondary metabolites in (a) $303 \mathrm{~K}$,

(b) $313 \mathrm{~K}$ and (c) $333 \mathrm{~K}$ on mild steel in salt water environment.

\subsection{Potentiodynamic Polarization Analysis and Result}

Tafel plots are representative plots demonstrating effects of inhibitors on either anodic dissolution of metals or hydrogen gas evolution reduction at the cathodic points [19] [22] [30] [37] [38] [39] [40]. These plots for the inhibition of AESML, SESML and FESML on mild steel in salt rich waters are represented in Figures 4(a)-(c). The corresponding data showing the kinetic and thermodynamic effects described by the plots are shown in Table 3. The data for $I E \%$ calculated from the corrosion curent density values as shown were obatined us- 
ing Equation (4) [22] [23] [24] [25] [41] [42].

$$
I E \%=\frac{I o_{\text {corr }}-I i_{\text {corr }}}{I o_{\text {corr }}} \times 100
$$

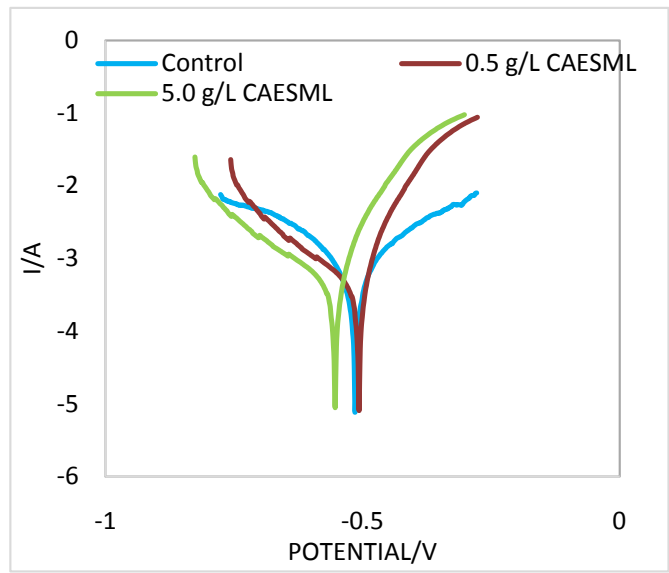

(a)

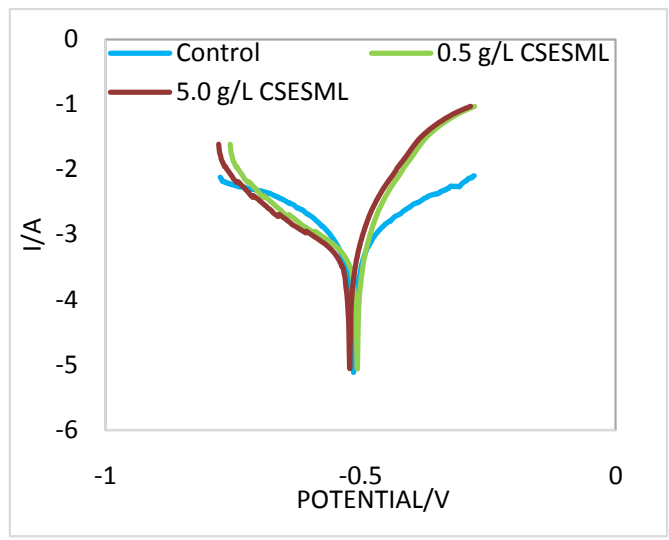

(b)

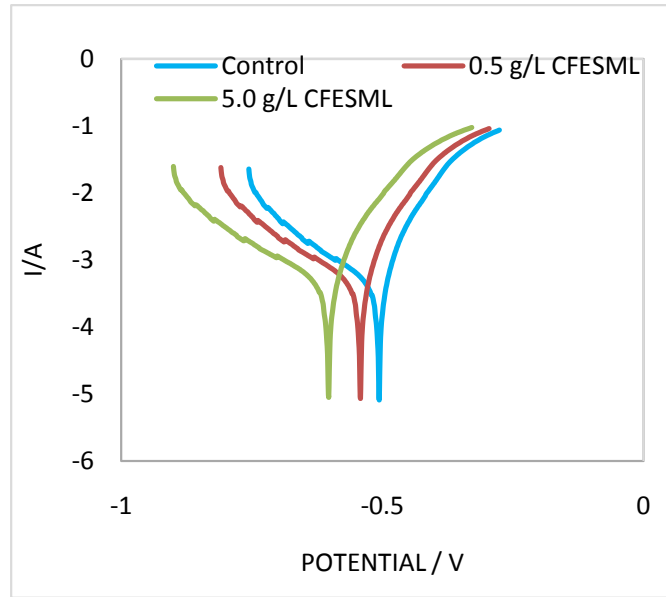

(c)

Figure 4. Tafel plots from the Potentiodynamic polarization data describing the inhibition of selected secondary metabolites ((a) Alkaloids, (b) Saponins and (c) Flavonoids natural product origin on mild steel in salt water environment). 
Table 3. Data analyses from the Tafel plots describing the inhibition of selected secondary of natural product origin on mild steel in salt water environment.

\begin{tabular}{lcccccc}
\hline & $\begin{array}{c}\text { Conc. } \\
(\mathrm{g} / \mathrm{L})\end{array}$ & $\begin{array}{c}I_{\text {corr }} \\
\left(\mathrm{mAcm}^{-2}\right)\end{array}$ & $\begin{array}{c}E_{\text {corr }} \\
(\mathrm{mV})\end{array}$ & $\begin{array}{c}\beta c \\
(\mathrm{mV} / \mathrm{dec})\end{array}$ & $\begin{array}{c}\beta a \\
(\mathrm{mV} / \mathrm{dec})\end{array}$ & $\begin{array}{c}I E \\
(\%)\end{array}$ \\
\hline \multirow{3}{*}{ AESML } & Control & 11.19 & -439 & 196 & 201 & - \\
& $0.5 \mathrm{~g} / \mathrm{L}$ & 4.37 & -311 & 114 & 116 & 60.95 \\
& $5.0 \mathrm{~g} / \mathrm{L}$ & 1.17 & -298 & 82 & 91 & 89.54 \\
SESML & $0.5 \mathrm{~g} / \mathrm{L}$ & 5.56 & -310 & 139 & 157 & 50.40 \\
& $5.0 \mathrm{~g} / \mathrm{L}$ & 3.23 & -215 & 107 & 110 & 71.14 \\
& $0.5 \mathrm{~g} / \mathrm{L}$ & 7.94 & -237 & 143 & 180 & 29.04 \\
\hline
\end{tabular}

where $I o_{\text {corr }}$ and $I i_{\text {corr }}$ represent the values of corrosion current densities with and without extract concentration, which was gotten through the plot of the cathodic and anodic slope drawn to the value of $E_{\text {corr }}$ Corrosion rate is proportional to corrosion current (corrosion current density). From Table 3, it is clear that values of $I_{\text {corr }}$ decrease with increased extract concentration for mild steel. This increase gave rise to maximum inhibition efficiency of 89.54, 71.14 and 68.10 for AESML, SESML and FESML respectively. This can be explained from the fact that the corrosion rate of steel in sea water is almost always rate limited by the cathodic reaction and by the mass transport of oxidizers (dissolved oxygen) to the surface hence, giving way for more inhibition at the anodic dissolution of the metal [14] [31] [40] [43] [44] [45]. Also the result confirmed the reduction in the loss of electrons at the anode by the inhibitors that would have trigger oxidation reaction that causes the anode to corrode [29] [39] [46] [47]. Corrosion potential is proportional to the thermodynamic values. Corrosion potential can show corrosion tendency but not rates. However, it's a property of a metal to lose electrons in the presence of an electrolyte. From the result, the corrosion potential values are increasing with increased inhibitor concentration signifying that the system will rather take up electrons than loose electrons, so a reduction is more likely than oxidation of the metal [26]-[31] [48] [49] [50]. But if corrosion potential was rather dropping, it implies oxidation of the reaction and accumulation of negative charges. So the high corrosion potential values exhibited by the inhibitors proved the inhibitors as good ones. Table 3 and Figures 4(a)-(c) also show a reduction in the corrosion rate and a negligible shift in the corrosion potential (in this case a slight increase) indicating that the inhibitors are mixed type inhibitors [44] [51] [52] [53]. This can also be confirmed from the anodic and cathodic slope values in Table 3.

\subsection{Electrochemical Impedance Spectroscopy Analysis and Result}

It is obvious while considering the plots in Figures 5(a)-(c) that the impedance behaviour profile was unaltered by the change in AESML, SESML and FESML, 
indicating a similar metal dissolution process in the presence and absence of the inhibitors [31] [37]. The high frequency semicircle at all concentrations of the inhibitors in Figures 5(a)-(c) represent the correlation of the capacitance $\left(C_{d l}\right)$ and the charge transfer resistance $\left(R_{c t}\right)$ in the metal dissolution steps that is inhibited, considering the fact that charge transfer resistance reflected the maximum inhibition efficiency obtained for mild steel at maximum concentration [25] [26] [27] [28] [29] [30] [54]. The data for the electrohemical parameters obtained using Nyquist curves are presented in Table 4. However, data of the double-layer capacitance for the semicircle were calculated using Equations (5) and (6).

$$
C_{d l}=1 /\left(\omega Z^{\prime \prime}\right)
$$

where $Z^{\prime \prime}$ is immaginay component of impedance at any frequency inside the semicircle and $\omega$ is the angular frequency.

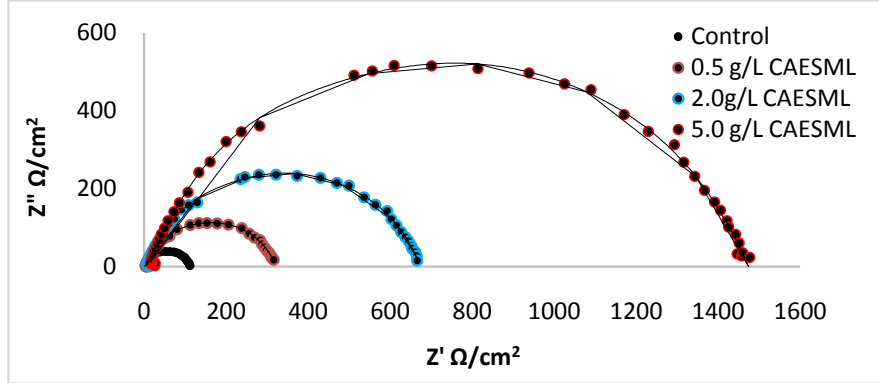

(a)

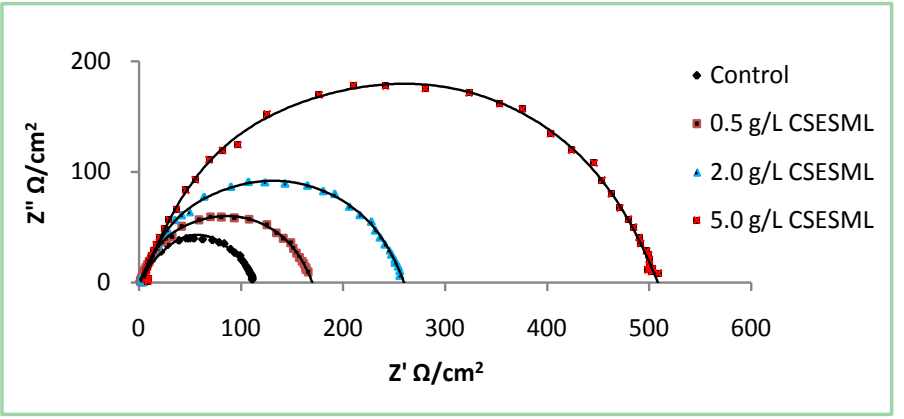

(b)

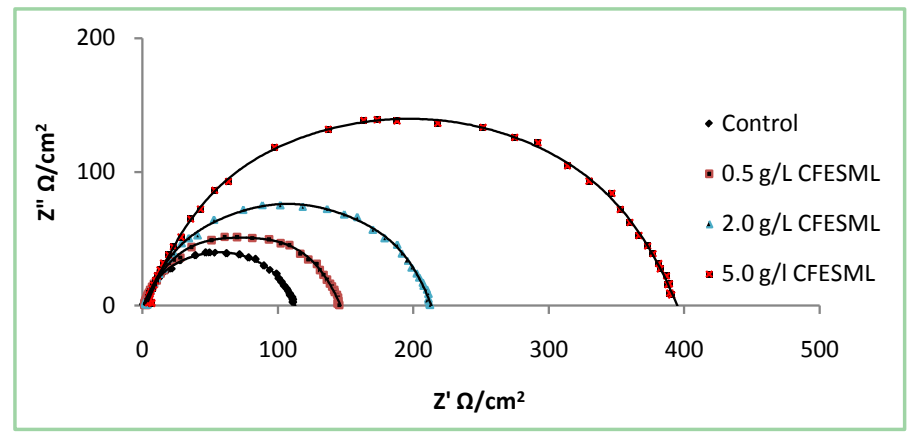

(c)

Figure 5. Representative Nyquist plots describing the inhibition of selected secondary metabolites ((a) Alkaloids, (b) Saponins and (c) Flavonoids natural product origin on mild steel in salt water environment). 
Table 4. Charge transfer resistance, double layer capacitance and inhibition efficiency values from the Nyquist plots describing the inhibition of selected secondary metabolites of natural product origin on mild steel in salt water environment.

\begin{tabular}{ccccc}
\hline $\begin{array}{c}\text { Conc. } \\
(\mathrm{g} / \mathrm{L})\end{array}$ & $\begin{array}{c}R_{c t} \\
\left(\Omega \cdot \mathrm{cm}^{-2}\right)\end{array}$ & $\begin{array}{c}C_{d l} \\
\left(\mu \mathrm{F} \cdot \mathrm{cm}^{-2}\right)\end{array}$ & $\% I E$ \\
\hline Control & 109 & 0.126 & - \\
\hline \multirow{2}{*}{ CAESML } & 337 & 0.0791 & 67.7 \\
& $2.5 \mathrm{~g} / \mathrm{L}$ & 676 & 0.0442 & 83.9 \\
& $5.0 \mathrm{~g} / \mathrm{L}$ & 1508 & 0.0202 & 92.8 \\
& $0.5 \mathrm{~g} / \mathrm{L}$ & 188 & 0.0848 & 42.0 \\
& $2.0 \mathrm{~g} / \mathrm{L}$ & 280 & 0.0672 & 61.1 \\
& $5.0 \mathrm{~g} / \mathrm{L}$ & 527 & 0.0407 & 79.3 \\
& $0.5 \mathrm{~g} / \mathrm{L}$ & 157 & 0.0892 & 30.6 \\
& $2.0 \mathrm{~g} / \mathrm{L}$ & 233 & 0.0711 & 53.2 \\
\hline & $5.0 \mathrm{~g} / \mathrm{L}$ & 392 & 0.0553 & 72.2 \\
\hline
\end{tabular}

But $\omega=2 * \pi * f_{\max }$ (in $\mathrm{Hz}$ used for measurement of EIS).

Hence,

$$
C_{d l}=1 /\left(2 \pi f_{\max } Z^{\prime \prime}\right)
$$

here $f_{\max }$ describe the maximun frequency of the semicircle and the $\pi$ is 3.142 .

However, the data for the $I E_{R} \%$ were obtained from the fitting of the charge transfer resistance values into Equation (7)

$$
I E_{R} \%=\frac{R_{c t}^{0}-R_{c t}^{i}}{R_{c t}^{0}} \times 100
$$

where $R_{c t}^{0}$ and $R_{c t}^{i}$ correspond to the charge ransfer values with and without the test solutions. From Table 4, also showed gradual decrease in the $C_{d l}$ data with inhibitors increase. This could be as a result of the inability of the double layer to allow the line up of charges and storage of electrical energy within [33] [48] [53] [55], consequence upon large surface area coverage effect of the inhibitor on the metal-surface interface. The decrease of double layer capacitance may also be due to the decrease of the area where electrolyte is present due to the formation of inhibitor film [19] [27] [53]. As more and more of either of these inhibitor molecules adsorbed on the surface, it can be seen that the inhibitor film capacitance becomes much lower references. This can explain why the $C_{d l}$ of the AESML is decreasing more compared to the rest informing its higher inhibition effectiveness.

\subsection{Enthalpy, Entropy, Free Energy and Activation Energy Evaluation}

Activation energy $E a$ is strictly combined with kinetics of chemical reactions. The relationship is described by the Arrhenius Equation (8) 


$$
C R=A \exp ((-E a) / R T)
$$

where $k$ is the rate coefficient, $A$ is the collision constatnt, $R$ is the universal gas constatnt, $T$ is the temperature (in Kelvin), $E a$ is the amount of energy required to ensure that a reaction happens.

By taking the log of Equation (8), Equation (9) was obtained.

$$
\ln C R=\ln A-\frac{E a}{R T}
$$

The plots obtained from the fitting of temperature dependent data into Equation (9) are shown in Figures 6(a)-(c). According to Equation (9), it is expected that the graph of $\ln C R$ vs $1 / T$ should have slope and intercept equal to $E a / R$ and $\log A$, respectively. In chemical kinetics, $E a$ is the height of the potential barrier separating the products and the reactants [11] [15]-[20] [42] [51]. According to Table 5, the values for the activation energy of the system were increasing with corresponding increase in the inhibitor concentration. These could mean a reduction in the frequency of successful chloride molecular collision, hence slower chemical reactions in respect to corrosion effects since reaction molecules can only complete the reaction once they have reached the top of the activation energy barrier [30] [31] [32] [33] [56]. Consequently, the inhibitor therefore has the potential of increasing the energy of the intermediate, reduce the number of collisions, reduce the number of particles that have enough energy to react and also reduce the number of corrosion reaction particles with the correct orientation, thereby slowing the transition from the reactants to the products (rate of reaction) at a given temperature [19] [37] [40]. It can also mean a physical adsorption following the large increase values of the activation energy in the inhibited solution compared to that of the control and values also been less than 20 $\mathrm{kJ} / \mathrm{mol}$ which is the threshold for phisisorption [22] [57] [58] [59].

Thermodynamic parameters for the adsorption of studied inhibitors were determined through transition state Equation (10) [21] [22] [23] [47] [49].

Table 5. Thermodynamic data for the inhibition of selected secondary metabolites of natural product origin on mild steel in salt water environment.

\begin{tabular}{ccccccccccc}
\hline & \multicolumn{3}{c}{ CAESML } & \multicolumn{3}{c}{ CSESML } & \multicolumn{3}{c}{ CFESML } \\
\hline Conc. (g/L) & $E a$ & $\Delta$ Hads kJ/mol & $\Delta$ Sads kJ/mol & $E a$ & $\Delta$ Hads kJ/mol & $\Delta$ Sads kJ/mol & $E a$ & $\Delta$ Hads kJ/mol & $\Delta$ Sads kJ/mol \\
\hline Control & 4.9 & 11.1 & -116.1 & 4.9 & 11.1 & -121.1 & 4.9 & 11.1 & -116.1 \\
$0.5 \mathrm{~g} / \mathrm{L}$ & 10.1 & 17.6 & -131.2 & 12.0 & 13.9 & -136.5 & 12.1 & 15.2 & -121.2 \\
$1.0 \mathrm{~g} / \mathrm{L}$ & 10.7 & 19.1 & -154.5 & 13.1 & 14.0 & -158.1 & 12.9 & 15.9 & -136.3 \\
$2.0 \mathrm{~g} / \mathrm{L}$ & 13.9 & 24.1 & -159.8 & 15.2 & 16.2 & -177.2 & 14.3 & 17.1 & -151.3 \\
$3.5 \mathrm{~g} / \mathrm{L}$ & 15.1 & 26.0 & -198.4 & 17.0 & 17.2 & -191.0 & 17.2 & 22.7 & -179.2 \\
$5.0 \mathrm{~g} / \mathrm{L}$ & 19.9 & 31.3 & -222.1 & 20.2 & 19.3 & -211.7 & 18.3 & 23.9 & -196.6 \\
\hline
\end{tabular}




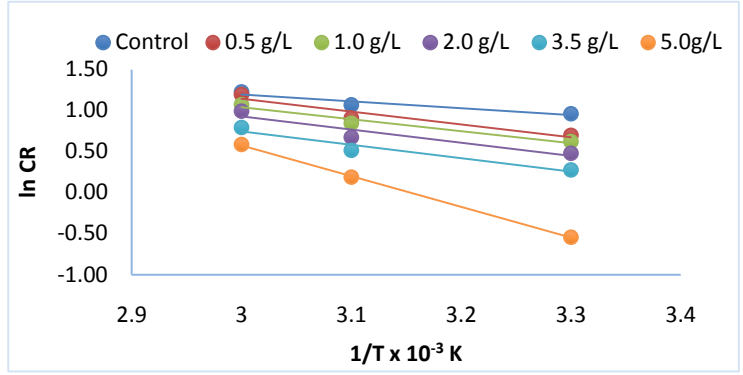

(a)

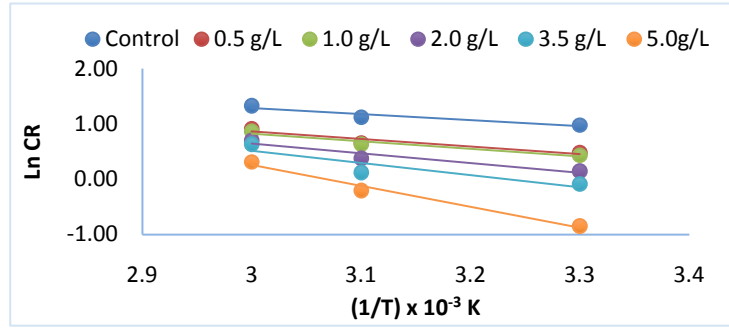

(b)

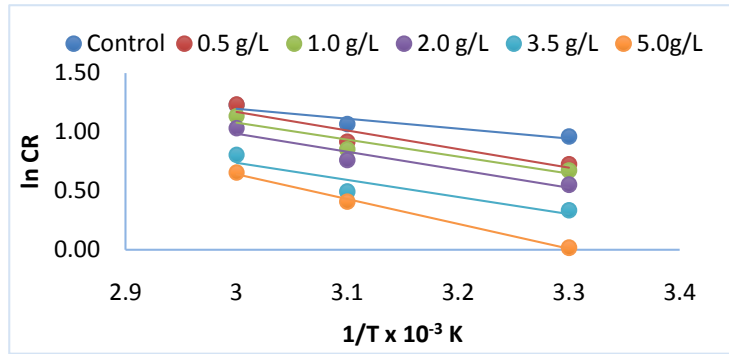

(c)

Figure 6. Arrhenius plots describing the inhibition of selected secondary metabolites ((a) Alkaloids, (b) Saponins and (c) Flavonoids) of natural product origin on mild steel in salt water environment.

$$
C R / T=\frac{K T}{h} \exp \left(\frac{\Delta S_{i}^{*}}{R}\right) \exp \left(\frac{-\Delta H_{i}^{*}}{R T}\right)
$$

where the gas constant is $R$, the temperature is $T$, the plank constant is $h, \Delta$ Hads the enthalpy and $\Delta$ Sads the entropy change.

Taking logarithm of Equation (10), yields Equation (11) upon rearrangement.

$$
\ln \frac{C R}{T}=\ln \frac{K}{h}+\frac{\Delta \text { Sads }}{R}-\frac{\Delta \text { Hads }}{R T}
$$

From Equation (18), a plot of $\ln (C R / T)$ versus $1 / T$ should be linear with slope and intercept equal to $\frac{\Delta \text { Hads }}{R}$ and $\ln \left(\frac{K}{h}\right)+\frac{\Delta \text { Sads }}{R}$, respectively.

The plots for the relationship between corrosion rate verse experimental temperatures aimed at determining the enthalpy and entropy of adsorption (transition state plots) are demonstrated in Figures 7(a)-(c). From Table 5, values of enthalpy of adsorption were seen to be positive which implies that heat flows (energy) from the surrounding into the reacting system (endothermic reaction). 
This means that the inhibitors have the potential of influencing the incoming energy in the system resulting in higher potential energy and lower kinetic energy, hence breaking up the intermolecular force between the molecules, leading to a slower corrosion reaction rate [15] [16] [17] [18] [19] [22] [31] [32] [33].

The inhibitor is also physically adsorbed on the surface being that the enthalpy values are within the threshold of physical adsorption $(<120 \mathrm{~kJ} / \mathrm{mol})$ [27] [29] [39] [40] [41] [42] [43], confirming the earlier assertion as captured in energy of activation, Ea. Meanwhile the entropy values were negative (Table 5), an indication of a lower amount of disorder and association of the inhibitor molecules [2] [7] [8] [30] [54]. This therefore explains the fact that they inhibitors therefore reduce the amount of kinetic energy established in the system hence reducing the excitation of the molecules and amount of random activity [8] [11] [47] [56].

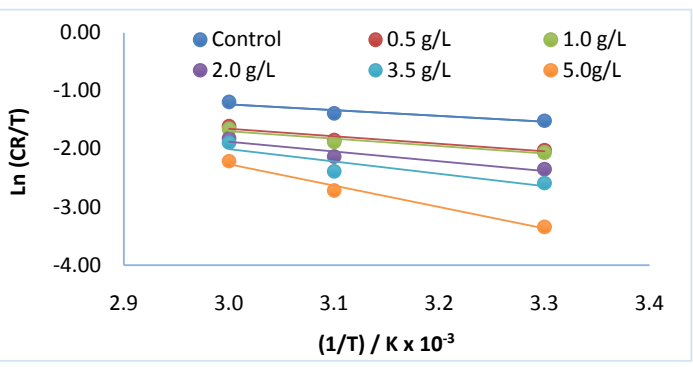

(a)

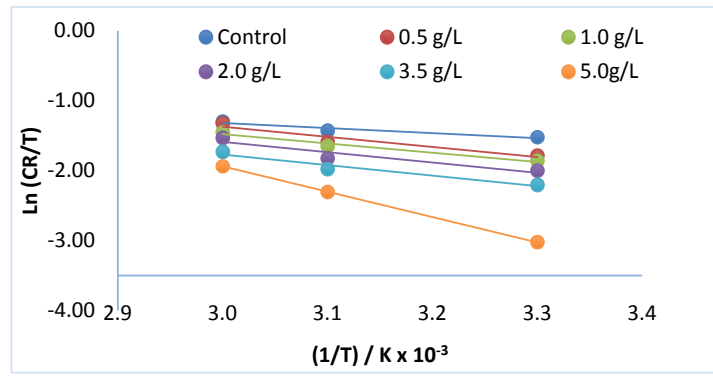

(b)

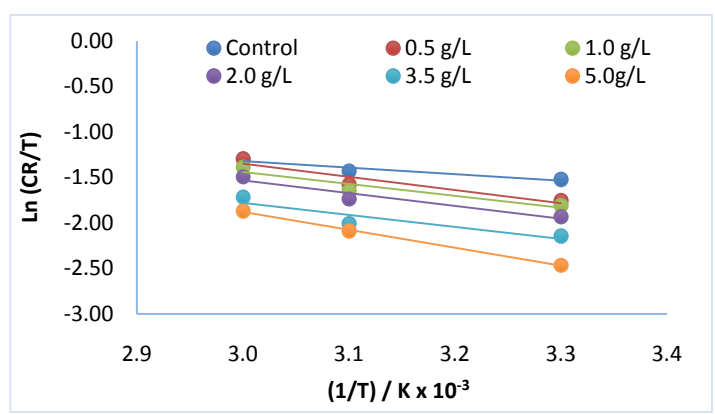

(c)

Figure 7. Plot of transition state describing the inhibition of selected secondary metabolites ((a) alkaloids, (b) Saponins and (c) Flavonoids natural product origin on mild steel in salt water environment). 
The standard free energy ( $\Delta$ Goads) of adsorption of the inhibitors recorded values lower than $-20 \mathrm{~kJ} / \mathrm{mol}$. Values at this range appeal to physisorption of the inhibitors [21] [27] [42] [50], and this confirmed the earlier results. Gibbs free energy values were less than zero (i.e. $\Delta G<0$ ) signifying that the inhibitor reaction is thermodynamically feasible, and inhibitors reaction is spontaneous at the forward direction. It also explains the stability of the inhibitors molecules on the metal surfaces [2] [17] [26] [51] [55] [56] [57] [58] [59]. This has been confirmed already from the result of entropy of adsorption.

\subsection{Adsorption Explanations}

In order to ascertain the nature of adsorption at the inhibitor/metal interface, adsorption isotherm, specifically Langmuir isotherm was employed. Langmuir adsorption Isotherm plots and data generated from the plots are presented in Figures 8(a)-(c) and Table 6, respectively. The Langmuir adsorption isotherm equation used for the plot of $C / \theta$ against Concentration is shown in Equation (12).

$$
\frac{C}{\theta}=\frac{1}{K}+C
$$

where $C$ represent extract concentration while $K$ is the binding constant of corrosion inhibition process. It was noticed from Table 6 that the binding constant values were increasing with increased temperature. This explains a greater binding affinity of the inhibitor molecules to the metal surface and also the fact that the inhibition will be in its best efficiency at lower temperatures and this is demonstrated in the gasometric experimentation [13] [19] [37] [56]. It also shows that the inhibitors are physically adsorbed on the metal surfaces. The regression values $\left(R^{2}\right)$ were very close to unity, an indication revealing the good fitting of the data to the isotherm and the fact that all the adsorbed inhibitor molecules are in contact with the surface layer of the adsorbent (mild steel) [42] [43] [44] [56] [59]. The slope value for the Langmuir plots is greater than unity, indicating a strong relationship between the species adsorbed.

Table 6. Adsorption data for the inhibition of selected secondary metabolites of natural product origin on mild steel in salt water environment.

\begin{tabular}{ccccccccccccccc}
\hline & \multicolumn{3}{c}{ CAESML } & \multicolumn{3}{c}{ CSESML } & \multicolumn{3}{c}{ CFESML } \\
\hline Temp. (K) & $k(\mathrm{~g} / \mathrm{L})$ & $R^{2}$ & Slope & $\begin{array}{c}\Delta G_{a d s}^{*} \\
(\mathrm{~kJ} / \mathrm{mol})\end{array}$ & $k(\mathrm{~g} / \mathrm{L})$ & $R^{2}$ & Slope & $\begin{array}{c}\Delta G_{\text {ads }}^{*} \\
(\mathrm{~kJ} / \mathrm{mol})\end{array}$ & $k(\mathrm{~g} / \mathrm{L})$ & $R^{2}$ & Slope & $\begin{array}{c}\Delta G_{\text {ads }}^{*} \\
(\mathrm{~kJ} / \mathrm{mol})\end{array}$ \\
\hline 303 & 5.730 & 0.998 & 1.035 & -14.518 & 2.591 & 0.997 & 1.045 & -12.515 & 2.242 & 0.997 & 1.049 & -12.154 \\
313 & 8.929 & 0.999 & 0.999 & -16.152 & 4.929 & 0.999 & 1.017 & -14.601 & 5.305 & 0.999 & 1.041 & -14.797 \\
333 & 11.236 & 0.998 & 0.992 & -17.820 & 6.101 & 0.998 & 0.992 & -16.125 & 6.321 & 0.999 & 1.014 & -16.227 \\
\hline
\end{tabular}




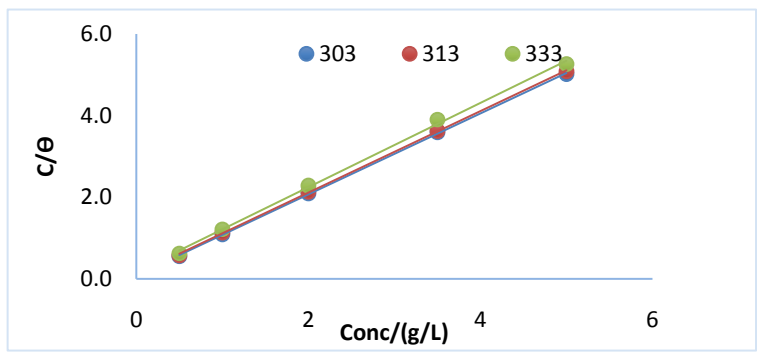

(a)

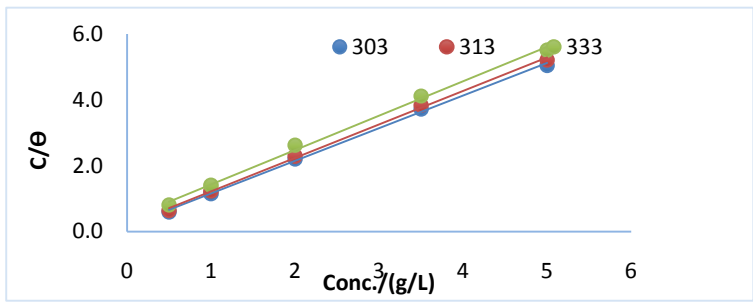

(b)

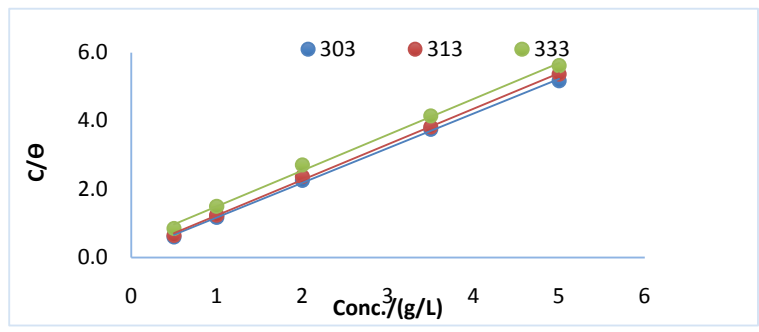

(c)

Figure 8. Adsorption plots describing the inhibition of selected secondary metabolites ((a) Alkaloids, (b) Saponins and (c) Flavonoids) of natural product origin on mild steel in salt water environment.

\section{Conclusions}

1) Strongylodon macrobotrys showed highest inhibition efficiency of $99.2 \%$, 92.6\% and $84.7 \%$ for AESML, SESML and FESML, respectively, as a result of strong adsorption of the molecules of the various inhibitors on the surface of the steel accounting for adequate substitution of water molecules on the surface by the inhibitors.

2) The inhibitors are proved to be thermodynamically feasible, very stabled and spontaneous in the forward direction as the Gibbs free energy of adsorption was less negative.

3) Both inhibitors were very active and adsorbed effectively as the charged transfer resistance increased and corrosion current density for the inhibitor/surface interface decreased appreciably.

4) The regression values $\left(R^{2}\right)$ were very close to unity, revealing the good fitting of the data to the Langmuir isotherm and the fact that all the adsorbed inhibitor molecules are in contact with the surface layer of the adsorbent.

5) Thermodynamic parameters confirmed that the inhibitors have the potential of influencing the incoming energy in the system resulting in higher poten- 
tial energy and lower kinetic energy, hence breaking up the intermolecular force between the molecules, leading to a slower corrosion reaction rate.

\section{Conflicts of Interest}

The authors declare no conflicts of interest regarding the publication of this paper.

\section{References}

[1] Pierre, R.R. (2000) Handbook of Corrosion Engineering. McGraw-Hill Pub., New York, 1125.

[2] Ugi, B.U., Obeten, M.E., Uwah, I.E. and Okafor, P.C. (2016) Aluminium Corrosion Abatement Using Non Toxic and Eco-Friendly Organic Inhibitors. Journal of Global Ecology and Environment, 4, 242-252.

[3] Popov, B.N. (2015) Corrosion Engineering Principles and Solved Problems. Elsevier, Amsterdam, 671.

[4] Okewale, A.O. and Olaitan, J.O. (2017) The Use of Rubber Leaf Extract as a Corrosion Inhibitor for Mild Steel in Acidic Solution. International Journal of Materials and Chemistry, 7, 13-23.

[5] Olesegun, S.J., Okoronkwo, E.A., Okotete, A.E. and Ajayi, O.A. (2016) Gravimetric and Electrochemical Studies of Corrosion Inhibition Potential of Acid and Ethanol Extract of Siam Weed on Mild Steel. Leonardo Journal of Sciences, 9, 42-55.

[6] Pathak, R.K. and Mishra, P. (2016) Drugs as Corrosion Inhibitors: A Review. International Journal of Science and Research, 5, 671-677. https://doi.org/10.21275/v5i4.NOV162623

[7] Karban, R. and Ian, T.B. (1997) Induce Responses to Herbivory. University of Chicago Press, Chicago, 627.

[8] Agosta, W. (1996) Bombardier Beetles and Fever Trees: A Close-Up Look at Chemical Warfare and Signals in Animals and Plants. Wesley House, Cheltenham, 724.

[9] Abdallah, M., Gad, E.A.M., Sobhi, M., Al-Fahemi, J.H. and Alfakeer, M.M. (2019) Performance of Tramadol Drug as a Safe Inhibitor for Aluminum Corrosion in 1.0 $\mathrm{M} \mathrm{HCl}$ Solution and Understanding Mechanism of Inhibition Using DFT. Egyptian Journal of Petroleum, 28, 173-181. https://doi.org/10.1016/j.ejpe.2019.02.003

[10] Rosenthal, G.A. and May, R.B. (1991) Interactions with Secondary Plant Metabolites. Academic Press, San Diego, 563.

[11] Abdallah, M., Zaafarany, I., Al-Karanee, I.O. and El-Fattah, A.A. (2012) Antihypertensive Drugs as an Inhibitors for Corrosion of Aluminum and Aluminum Silicon Alloys in Aqueous Solutions. Arabian Journal of Chemistry, 5, 225-234. https://doi.org/10.1016/j.arabjc.2010.08.017

[12] Abdollahi, F., Foroughi, M.M., Zandi, S.M. and Kazemipour, M. (2020) Electrochemical Investigation of Meloxicam Drug as a Corrosion Inhibitor for Mild Steel in Hydrochloric and Sulfuric Acid Solutions. Progress in Color, Colorant and Coating, 13, 155-165.

[13] Atheel, H.A., Dhuha, H.F., Ali, A.A., Abdul, H.F. and Yousif, E. (2017) Inhibitive Effect of Atenolol on the Corrosion of Zinc in Hydrochloric Acid. Rasayan Journal of Chemistry, 10, 922-928.

[14] Bashir, S., Sharma, V., Kumar, S., Ghelichkhah, Z., Obot, I. and Kumar, A. (2020) Inhibition Performances of Nicotinamide against Aluminum Corrosion in an Acid- 
ic Medium. Portugaliae Electrochimica Acta, 38, 107-123. https://doi.org/10.4152/pea.202002107

[15] Bensouda, Z., Elassiri, E., Galai, M., Sfaira, M., Farah, A. and Touhami, M.E. (2018) Corrosion Inhibition of Mild Steel in $1 \mathrm{M} \mathrm{HCl} \mathrm{Solution} \mathrm{by} \mathrm{Artemisia} \mathrm{abrotanum}$ Essential Oil as an Eco-Friendly Inhibitor. Journal of Materials and Environmental Sciences, 9, 1851-1865.

[16] Santosa, A., Almeida, T., Cotting, F., Aoki, I.V., Melo, H.G. and Capelossi, V.R. (2017) Evaluation of Castor Bark Powder as a Corrosion Inhibitor for Carbon Steel in Acidic Media. Materials Research, 20, 492-505. https://doi.org/10.1590/1980-5373-mr-2016-0963

[17] Singh, A., Ansari, K.R., Quraishi, M.A. and Lin, Y. (2019) Investigation of Corrosion Inhibitors Adsorption on Metals Using Density Functional Theory and Molecular Dynamics Simulation. Intechopen, London, 1-19.

https://doi.org/10.5772/intechopen.84126

[18] Verma, C., Chauhan, D.S. and Quraishi, M.A. (2017) Drugs as Environmentally Benign Corrosion Inhibitors for Ferrous and Nonferrous Materials in Acid Environment: An Overview. Journal of Materials and Environmental Sciences, 8, 4040-4051.

[19] Bharatiya, U., Gal, P., Agrawal, A., Shah, M. and Sircar, A. (2019) Effect of Corrosion on Crude Oil and Natural Gas Pipeline with Emphasis on Prevention by Ecofriendly Corrosion Inhibitors: A Comprehensive Review. Journal of Bio- and Tribo-Corrosion, 5, 35. https://doi.org/10.1007/s40735-019-0225-9

[20] Geethamani, P., Narmatha, M., Dhanalakshmi, R., Aejitha, S. and Kasthuri, P.K. (2019) Corrosion Inhibition and Adsorption Properties of Mild Steel in $1 \mathrm{M} \mathrm{Hy}$ drochloric Acid Medium by Expired Ambroxol Drug. Journal of Bio- and Tribo-Corrosion, 5, 1-8. https://doi.org/10.1007/s40735-018-0205-5

[21] Hassan, K.H., Khadom, A.A. and Kurshed, N.H. (2016) Citrus Aurantium Leaves Extracts as Sustainable Corrosion Inhibitor of Mild Steel in Sulfuric Acid. South African Journal of Chemical Engineering, 22, 1-5. https://doi.org/10.1016/j.sajce.2016.07.002

[22] He, T., Emori, W., Zhang, R., Okafor, P.C., Yang, M. and Cheng, C. (2019) Detailed Characterization of Phellodendron chinense Schneid and Its Application in the Corrosion Inhibition of Carbon Steel in Acidic Media. Bioelectrochemistry, 130, Article ID: 107332. https://doi.org/10.1016/j.bioelechem.2019.107332

[23] Hebbar, N., Praveen, B.M., Prasanna, B.M. and Sachin, H.P. (2018) Anticorrosion Potential of Flectofenine on Mild Steel in Hydrochloric Acid Media: Experimental and Theoretical Study. Journal of Failure Analysis and Prevention, 1, 371. https://doi.org/10.1007/s11668-018-0416-6

[24] Ikpi, M.E. and Abeng, F.E. (2018) Theoretical Study on the Corrosion Inhibitor Potential of Moxifloxacin for API 5L X-52 Steel in Acidic Environment. International Conference on Science and Sustainable Development, Earth and Environmental Science, Vol. 173, 1-7. https://doi.org/10.1088/1755-1315/173/1/012018

[25] Kumar, D., Jain, V. and Rai, B. (2018) Unravelling the Mechanisms of Corrosion Inhibition of Iron by Henna Extract: A Density Functional Theory Study. Corrosion Science, 142, 102-109. https://doi.org/10.1016/j.corsci.2018.07.011

[26] Lgaz, H., Salghi, R., Jodeh, S. and Hammouti, B. (2017) Effect of Clozapine on Inhibition of Mild Steel Corrosion in 1.0 M HCl Medium. Journal of Molecular Liquids, 225, 271-280. https://doi.org/10.1016/j.molliq.2016.11.039

[27] Boumhara, K., Harhar, H., Tabyaoui, M., Bellaouchou, A., Guenbour, A. and Zarrouk, A. (2019) Corrosion Inhibition of Mild Steel in $0.5 \mathrm{M} \mathrm{H}_{2} \mathrm{SO}_{4}$ Solution by Ar- 
temisia Herba-Alba Oil. Journal of Bio- and Tribo-Corrosion, 5, 1-8. https://doi.org/10.1007/s40735-018-0202-8

[28] Fouda, A.S. and Gadow, H.E. (2014) Streptoquin and Septazole: Antibiotic Drugs as Corrosion Inhibitors for Copper in Aqueous Solutions. Global Journal of Researches in Engineering. Chemical Engineering, 14, 1-17.

[29] Gadow, H.S. and Motawea, M.M. (2017) Investigation of the Corrosion Inhibition of Carbon Steel in Hydrochloric Acid Solution by Using Ginger Roots Extract. RSC Advances, 7, 24576-24588. https://doi.org/10.1039/C6RA28636D

[30] Louis, H., Japari, J., Sadia, A., Philip, M. and Bamanga, A. (2017) Photochemical Screening and Corrosion Inhibition of Poupartia birrea Back Extract as a Potential Green Inhibitor for Mild Steel in $0.5 \mathrm{M} \mathrm{H}_{2} \mathrm{SO}_{4}$ Solution. World News of Natural Sciences, 10, 100-112.

[31] Vorobyova, V. and Skiba, M. (2020) Apricot Pomace Extract as a Natural Corrosion Inhibitor of Mild Steel Corrosion in $0.5 \mathrm{M} \mathrm{NaCl}$ Solution: A Combined Experimental and Theoretical Approach. Journal of Chemical Technology and Metallurgy, 55, 210-222.

[32] Wang, X., Jiang, H., Zhang, D. and Zhou, W.-J. (2019) Solanum lasiocarpum L. Extract as Green Corrosion Inhibitor for A3 Steel in $1 \mathrm{M} \mathrm{HCl} \mathrm{Solution.} \mathrm{International}$ Journal of Electrochemical Science, 14, 1178-1196. https://doi.org/10.20964/2019.02.06

[33] Solomon, M.M., Umoren, S.A., Quraishia, M.A., Tripathi, D. and Abai, E.J. (2020) Effect of Akyl Chain Length, Flow, and Temperature on the Corrosion Inhibition 1 of Carbon 2 Steel in a Simulated Acidizing Environment by an Imidazoline-Based Inhibitor. Journal of Petroleum Science and Engineering, 187, Article ID: 106801. https://doi.org/10.1016/j.petrol.2019.106801

[34] Srinivasulu, A. and Kasthuri, P.K. (2017) Study of Inhibition and Adsorption Properties of Mild Steel Corrosion by Expired Pharmaceutical Gentamicin Drug in Hydrochloric Acid Media. Oriental Journal of Chemistry, 33, 2616-2624. https://doi.org/10.13005/ojc/330559

[35] Su, P., Li, L., Li, W., Huang, C., Wang, X., Liu, Y. and Singh, A. (2020) Expired Drug Theophylline as Potential Corrosion Inhibitor for 7075 Aluminum Alloy in 1 $\mathrm{M} \mathrm{NaOH}$ Solution. International Journal of Electrochemical Science, 15, 1412-1425. https://doi.org/10.20964/2020.02.25

[36] Umoren, S.A. and Solomon, M.M. (2015) Effect of Halide Ions on the Corrosion Inhibition Efficiency of Different Organic Species: A Review. Journal of Industrial and Engineering Chemistry, 21, 100-107. https://doi.org/10.1016/j.jiec.2014.09.033

[37] Uwah, I.E., Ugi, B.U., Okafor, P.C. and Ikeuba, A.I. (2013) Comparative Study of Corrosion Inhibition and Adsorption Characteristics of Ethanol Extracts of Andrographis paniculata (King Bitters) and Vernonia amygdalina (Bitter Leaf) on Mild Steel in $\mathrm{HCl}$ Solution. International Journal of Applied Chemistry, 9, 73-88.

[38] Yadav, M., Kumar, S., Kumari, N., Bahadur, I. and Ebenso, E.E. (2015) Experimental and Theoretical Studies on Corrosion Inhibition Effect of Synthesized Benzothiazole Derivatives on Mild Steel in $15 \% \mathrm{HCl}$ Solution. International Journal of Electrochemical Science, 10, 602-624.

[39] Yadav, M., Sinha, R.R., Kumar, S. and Sharka, T.K. (2015) Corrosion Inhibition Effect of Spiropyrimidinethiones of Mild Steel in $15 \% \mathrm{HCl}$ Solution: Insight from Electrochemical and Quantum Studies. RSC Advances, 5, 70832-70848. https://doi.org/10.1039/C5RA14406J

[40] Majda, M.T., Ramezanzadeh, M., Ramezanzadeh, B. and Bahlakeh, G. (2020) Pro- 
duction of an Environmentally Stable Anti-Corrosion Film Based on Esfand Seed Extract Molecules-Metal Cations: Integrated Experimental and Computer Modeling Approaches. Journal of Hazardous Materials, 382, 1-16. https://doi.org/10.1016/j.jhazmat.2019.121029

[41] Ngobiri, N.C., Oguzie, E.E., Li, Y., Liu, L., Oforka, N.C. and Akaranta, O. (2015) Eco-Friendly Corrosion Inhibition of Pipeline Steel Using Bressica oleracea. International Journal of Corrosion, 2015, Article ID: 404139.

https://doi.org/10.1155/2015/404139

[42] Ngobiri, N.C., Oguzie, E.E., Oforka, N.C. and Akaranta, O. (2019) Comparative Study on the Inhibitive Effect of Sulfadoxine-Pyrimethamine and an Industrial Inhibitor on the Corrosion of Pipeline Steel in Petroleum Pipeline Water. Arabian Journal of Chemistry, 12, 1024-1034. https://doi.org/10.1016/j.arabjc.2015.04.004

[43] Akalezi, C.O. and Oguzie, E.E. (2016) Evaluation of Anticorrosion Properties of Chrysophyllum albidum Leaves Extract for Mild Steel Protection in Acidic Media. International Journal of Industrial Chemistry, 7, 81-92. https://doi.org/10.1007/s40090-015-0057-5

[44] Ali, I.H. and Suleiman, H.A. (2018) Effects of Acid Extract of Leaves of Juniperus procera on Corrosion Inhibition of Carbon Steel in $\mathrm{HCl}$ Solution. International Journal of Electrochemical Science, 13, 3910-3922. https://doi.org/10.20964/2018.04.01

[45] Davanya, D.K., Frank, V.P. and Vijaya, D.P. (2020) Green Approach to Corrosion Inhibition of Mild Steel in Hydrochloric Acid by 1-[Morphholin-4-yl(thiophen-2yl)methyl]thiourea. Journal of Failure Analysis and Prevention, 20, 494-502. https://doi.org/10.1007/s11668-020-00850-9

[46] Alibakhshi, E., Ramezanzadeh, M., Bahlakeh, G., Ramezanzadeh, B., Mahdavian, M. and Motamedi, M. (2018) Glycyrrhiza glabra Leaves Extract as a Green Corrosion Inhibitor for Mild Steel in $1 \mathrm{M}$ Hydrochloric Acid Solution: Experimental, Molecular Dynamics, Monte Carlo and Quantum Mechanics Study. Journal of Molecular Liquids, 6, 265. https://doi.org/10.1016/j.molliq.2018.01.144

[47] Al-Shehri, D.A. (2019) Oil and Gas Wells: Enhanced Wellbore Casing Integrity Management through Corrosion Rate Prediction Using an Augmented Intelligent Approach. Sustainability, 11, 1-18. https://doi.org/10.3390/su11030818

[48] Ameh, P.O. and Eddy, N.O. (2016) Theoretical and Experimental Studies on the Corrosion Inhibition Potentials of 3-Nitrobenzoic Acid for Mild Steel in 0.1 M $\mathrm{H}_{2} \mathrm{SO}_{4}$. Cogent Chemistry, 2, 125. https://doi.org/10.1080/23312009.2016.1253904

[49] Ameh, P.O. and Eddy, N.O. (2018) Experimental and Computational Chemistry Studies on the Inhibition Efficiency of Phthalic Acid (PHA) for the Corrosion of Aluminum in Hydrochloric and Tetraoxosulphate (VI) Acids. Protection of Metals and Physical Chemistry of Surfaces, 54, 1169-1181.

[50] Ammal, P.R., Prajila, M. and Joseph, A. (2018) Effective Inhibition of Mild Steel Corrosion in Hydrochloric Acid Using EBIMOT, 1,3,4-Oxadiazole Derivative Bearing a 2-Ethlbenzimidazole Moiety: Electro Analytical, Computational and Kinetic Studies. Egyptian Journal of Petroleum, 27, 823-833.

https://doi.org/10.1016/j.ejpe.2017.12.004

[51] Cookey, G.A., Tambari, B.L. and Iboroma, D.S. (2018) Evaluation of Corrosion Inhibition Potentials of Green Tip Forest Lily (Clivia nobilis) Leaves Extract on Mild Steel in Acid Media. Journal of Applied Sciences and Environmental Management, 22, 90-94. https://doi.org/10.4314/jasem.v22i1.16

[52] Dagdag, O., El Harfi, A., Cherkaoui, O., Safi, Z., Wazzan, L.G., Akpan, E.D., Verma, 
C., Ebenso, E.E. and Jalgham, T.T. (2019) Rheological, Electrochemical, Surface, DFT and Molecular Dynamics Simulation Studies on the Anticorrosive Properties of New Epoxy Monomer Compound for Steel in $1 \mathrm{M} \mathrm{HCl}$ Solution. RSC Advances, 9, 4454-4462. https://doi.org/10.1039/C8RA09446B

[53] Evgeniji, B. and Macdonald, R.J. (225) Impedance, Spectroscopy, Theory and Experiment. 2nd Edition, John Wiley and Son Pub., Hoboken, 583.

[54] Fajobi, M.A., Fayomi, O.S.I., Akande, I.G. and Odunlami, O.A. (2019) Inhibitive Performance of Ibuprofen Drug on Mild Steel in $0.5 \mathrm{M}$ of $\mathrm{H}_{2} \mathrm{SO}_{4}$ Acid. Journal of Bio- and Tribo-Corrosion, 5, 79. https://doi.org/10.1007/s40735-019-0271-3

[55] Fouda, A., El-Abbasy, H.M. and El-Sherbini, A.A. (2018) Inhibitive Effect of Artmisia judaica Herbs Extract on the Corrosion of Carbon Steel in Hydrochloric Acid Solutions. International Journal of Corrosion and Scale Inhibition, 2, 213-235.

[56] Ngobiri, N.C. and Okorosaye-Orubite, K. (2018) Corrosion Pattern of Pipeline Steel in Petroleum Pipeline Water in the Presence of Biomass Derived Extracts of Brassica oleracea and Citrus paradise Mesocarp. Materials Sciences and Applications, 9, 216-141. https://doi.org/10.4236/msa.2018.91009

[57] Rodic, P. and Milosev, I. (2019) The Influence of Additional Salts on Corrosion Inhibition by Cerium (III) Acetate in the Protection of AA 7075-T6 in Chloride Solution. Corrosion Science, 149, 108-122. https://doi.org/10.1016/j.corsci.2018.10.021

[58] Sangeetha, C. and Chinnakani Selvaraj, S. (2020) Jatropha gossyfolia-A Green Inhibitor Act as Anticorrosive Agent on Carbon Steel. Journal of Advanced Scientific Research, 11, 180-186.

[59] Yetri, Y. (2017) Green Inhibitor for Mild Steel in Acidic Solution by Using Crude Extract and Polar Extract of Theobroma cacao Peels. Oriental Journal of Chemistry, 33, 2071-2079. https://doi.org/10.13005/ojc/330456 